\title{
Phonology: Tool for Poetic Analysis
}

\author{
Mohan Kumar Tumbahang
}

\begin{abstract}
This article aims to focus on how the linguistic sound patterns can be a significant tool in literary analysis specifically in the analysis of the literary genre poetry. It attempts to discuss about the crucial points for successful poetic analysis through linguistic sounds which is technically termed as phonemes. To deal with this issue, the article writer has formed a mindset to avail the qualitative research method or the study is based on non-numerical data. The method being the qualitative one, the library consultation and empirical insight are a must. It is fairly expected that the article can be of certain help to the language learners, language teachers, critics, course designers and planners of teaching materials. The article has drawn the conclusion that phonology can be significant means for interpreting the poetic text. The poetic texts/discourses can be analyzed in terms of the frequency of certain sounds' recurrence. In other words, prosody, tone (author's attitude), and verse types can be analyzed through the linguistic sound pattern.
\end{abstract}

Keywords: Alliteration, analysis, metric foot, rhyme, rhythm, verse.

\section{Background}

The term 'phonology' can be less frequent and less familiar in the field of poetry. The students or even teachers who are just involved in the literary studies may not realize the fact that there is a very close relationship between phonology and poetry. Likewise, the personalities solely dealing with the discipline of linguistics can have less idea that phonology has predominant role in the poetic creation. Both parties (i.e. literary figures and linguists) may not be, thus much aware of the usefulness of the phonology in the creation/composition and analysis of the poetry as well. Keeping this idea in the mind, this article attempts to discuss the issue how phonology serves the basic element of sound patterns to the poetry and how it heightens the desired effect in the poetry through the medium of sound combination. Phonology, being one of the major branches of linguistics especially dealing with sound pattern of language, plays a crucial role in the creation of the poetry. Regarding the goal of phonological study David Crystal states, "The primary aim of phonology is to discover the principles that govern the way the sounds are organized in language and to explain the variations that occur" (162). The statement implies that phonology can be a very useful and 
basic tool for the analysis of the poetry. It is, in fact, very interesting matter to observe how phonology can make a significant contribution to the analysis of the poetry. The idea that phonological patterns in poetic composition, can be helpful for the students and teachers of both disciplines (linguistics and literature).

In poetic analysis, merely the segmental phonology cannot do the fuller justice to the expected range of poetic effects. It is worth consideration that the phonology appears to have multi-faceted dimensions. For the wider range of poetic analysis, the phonological pattern should be viewed from three perspectives. The first basic kind that is inevitable in both the speech and writing forms is segmental phonology. Vowels and consonants are considered to be segmental sounds because they are discrete and uttered in short durations. Segments are called 'discrete' because they are at least, at some analytical level, separate and individual, temporally ordered. These segments are combined to produce syllables, words and sentences - the 'verbal aspect' of language. The second type is supra-segmental phonology. Regarding the suprasegmental phonology, Ladefoged considers as, "supra-segmental features are those aspects of speech that involve more than single consonants and vowels" (225). It refers to a phonological property more than one sound segment. While considering it minutely Ogden views that suprasegmental information implies to several different phenomena (i.e. pitch, loudness, tempo, juncture, duration, etc.) In this sense, supra-segmental features are often called as "musical" aspects of speech. There are a number of authors dealing with the sound system (phonetics and phonology) however the authors' number is relatively smaller who have observed and analyzed the poetic discourses from the phonological (linguistic) point of view. To name only a few authors who are dealing with phonology in relation to poetic analysis are as: Jakobson (1960), Traugott and Pratt (1980), Thornborrow and Wareing (1998), Lazar (1999), and Simpson (2012).

The third and newly emerged phonological sub-category is the auto-segmental phonology. This framework of phonological analysis was first proposed by John Goldsmith in his PhD dissertation (1976) at the MIT University America. However, Goldsmith's idea was initiated quite earlier by the various linguists notably, Bernard Bloch (1948), J. R. Firth (1948), and Charles Hockett (1955). In general, auto-segmental phonology is a non-linear approach to phonology that allows phonological processes, such as tone and vowel harmony, to be independent of and extend beyond individual consonants and vowels. Actually, negating the difference between segmental and supra-segmental is what auto-segmental phonology is all about (see Goldsmith 1976 and similar publications of the era). Auto-segmental phonology does not take the segment to be the representational primary, it takes the feature to be primary (each feature is "its own segment"), thus each feature has full autonomy in the way that tone classically is autonomous from the segment. 


\section{Objectives of the Study}

The objectives of this study are:

- To point out linguistic sounds and their general phonological features

- To discuss about how these linguistic sounds contribute to the poetic constructions and analysis

\section{Methodology Used}

The study is entirely based on the qualitative research method in which non-numerical data are collected and described. In order to meet the set objectives, the study avails the qualitative method which may attempt to gain a deeper understanding of the proposed issue or the phenomenon because it is a reliable research design for gathering non-numerical data. Moreover, this type of research refers to the meanings, concepts, definitions, or characteristics. The necessary data will be based on empirical insights as well as library consultation. The basic theory it intends to follow is from the writings of linguistics by Jakobson (1960), Goldsmith (1972), Traugott and Pratt, (1980), and Simpson (2012).

\section{Phonology and Significant Role in Poetic Analysis}

A close analysis of the poetic text generally reveals that "the sound patterns of language constantly influence an author's choice of words, as well as influencing the sound composition of the words available to choose from" (Traugott and Pratt 68). The consonant sound patterning is almost always necessary to be identical for both rhyme and alliteration. Likewise, the vowel sounds are required not only to form syllables in the word but also the assonance. Therefore, the linguistic sound pattern (phonology) can play an obvious role in constructing phonological cohesion in poetry by means of rhyme, assonance and alliteration. Though sounds themselves have no meanings, they can create the complex kind of cohesion by interaction of phonological patterns with meaning patterns. This means that "there are ways of using sounds to complement meaning" (Traugott and Pratt 69). The famous verse line "The Sound must seem an Echo to the Sense" by Alexander Pope in Essay on Criticism hints at the sounds subordination to the meaning. The following are the specific dimensions of how the phonological pattern plays vital role in the interpretation of poetic discourse.

\section{Phonology (Sound Pattern) and Analysis through the Prosodic Aspect}

Phonology is one of the linguistic levels that deals with the meaningful linguistic sounds. In other words, it "refers to the smallest perceptible discrete segment of sound in a stream of speech" (Crystal 361). It implies that humans can produce many sounds but all sounds cannot be the linguistic sounds. e.g. hiccough, sneezing, snorting, or pattering are sounds but they are not linguistically meaningful, and thus they are not included as being the linguistic sounds. 
114 JODEM: Journal of Language and Literature, vol. 10, no. 1, issue 12, 2019/2076BS

Now, it is better to turn towards the issue how the linguistic sound system plays crucial role in the pattern of language and in the analysis of the text especially the poetry. The English language has forty four sounds in which twenty four are consonants, and twenty are vowel sounds. Of the twenty vowel sounds, twelve are monophthongs (also termed as pure vowel where there is no detectable change in quality during a syllable) while the eight are diphthongs (i.e. vowels which change in quality are known as diphthongs and triphthongs as in 'here' /heə(r)/ and 'fire' /farə(r)/ respectively.

Almost all the literary texts are composed of the linguistic sounds as they are sequenced in a linear order. Moreover, the matter of fact is that the linguistic sounds are the basic elements or substances for the language pattern. Even though the sound segments are inevitable for all sorts of literary texts, they are highly considered while looking into the poetic creations. Concerning the analysis of poetic texts, the sounds are considered to have the double roles as "prosodic phonology and the prosody" (Firth 1-32). The phonemes (sounds) being discussed of having the two analytic categories are termed as 'phonematic units' which "comprise consonants and vowels, occurring in linear sequence which cannot be handled in terms of prosodies" (Crystal 361). In poetical analysis, the linguistic sounds related interpretative points are as follows:

Meter (Greek measure): From the surface view, the meter may not necessarily be appearing to have nexus with sound pattern, but the pattern of sounds seems to be crucial as it is considered very minutely. Obviously, the basic unit of the meter is supposed to be made up of the sounds. For example, the basic unit of the meter is the syllable and this syllable is formed by the presence of vowel sound. So the analysis of a poem will be incomplete unless there is the mention of meter. It may also be equally common that the beginners of the poetry may raise the question about the meter and its significance.

Meter may be defined as that ordered rhythm which results from regular alternation of stressed and unstressed or as they are sometimes called, long and short, syllables in a line of poetry. In many Western classical poetic traditions, the meter of a verse can be described as a sequence of feet, each foot being a specific sequence of syllable types-such as relatively unstressed/stressed (the norm for English poetry) or long/short (as in most classical Latin and Greek poetry). "The term 'meter' refers to the pattern of stressed and unstressed syllables in verse" (Cuddon 509). Here, about the syllable Bose and Sterling state, "a syllable is a word containing only one vowel sound, irrespective of vowels and consonants that can be uttered at a single effort of the voice. It may be either of accented or unaccented" (126). In other words, a 'syllable' means a unit of pronunciation having one vowel sound, with or without surrounding consonants, forming the whole or a part of a word; for example, the word 'education' /e.dzv.keI. $\mathrm{n} /$ has four syllables since there are four syllabic sounds as /e/, / //, /ei/ and $/ \mathrm{n} /$. Although the $/ \mathrm{n} /$ is the consonant sound, it forms syllable when it occurs at the 
word final. In English, the consonant sounds /n/ and /1/ are known as syllabic consonants in the condition that they should come at the word final position.

The metrical system of the world's poetry can be divided into two major patterns as qualitative meter based on stressed syllable coming at regular interval and quantitative meter based on syllable weight rather than stress. The usual type of English-language poetry is the qualitative meter whereas the Sanskrit and classical Arabic poetry is based on quantitative meter.

In the case of metrical versed (poetic line) poem, the preceding and subsequent verses (poetic lines) must have equal number of syllables. Thus, linguistic sounds can play the predominant role in the metrical pattern of poetry. While trying to analyze the English poetry, one should consider the significant poetic registers like caesura (natural pause occurring in the middle of a poetic line), enjambment (by contrast with caesura, incomplete syntax at the end of a line or the meaning runs over from the one poetic line to other), and metric variations (inversion of a foot i.e. change iambic foot into trochaic foot within a stanza, headless verse which lacks the first syllable of the first foot, and catalexis which suggests the reduction of the final line to one or two feet)

Rhythm (Greek - flow): Rhythm typically falls under the poetic composition. It is generally defined as the regular sequence of stressed and unstressed or vice versa syllables in a verse line. Of the rhythm Wales states, "In phonetics and prosody rhythm is generally described as the perceptual pattern of accented or stressed and unaccented or unstressed syllables in a language" (348). Rhythm is also, thus, determined by the help of the syllable which is constituted by the vowel sounds. It is one of the major components of the musical pattern. Not always, but in general major word class i.e. noun, adjective, verb, and adverb are stressed while minor word class that is, pronoun, article, conjunction, auxiliary verb and preposition do not receive the stress or they are unstressed terms. In the case of disyllabic or trisyllablic major word class, the word usually has the stress in the first syllable. e.g. 'water', 'yesterday' (the remaining syllables are unstressed) here one thing to remember is that how many syllables a word may have but there is only one stressed syllable out of them.

Rhyme/Rime (Greek - flow): Rhyme is another significant element of the musicality in poetry which is generally defined as the repetition of similar sound of the middle of the verse line with the ending of the same line (intra-line rhyme) and the ending sound in two or more than two lines (inter-line rhyme). Obviously, metrical poetry has rhyme scheme in different patterns as the two lines rhyming together (aa, bb, cc), alternative line rhyming (abab, bcbc cdcd), first line rhymes with fourth line and middle two lines rhyme together (abba, abba). However, metrical verses do not necessarily have the rhyme scheme, and such verse lines are termed as the blank verse. The terms 'rhyme' and 'metrical form' are determinant to certain 
poetic trends and conventions. For instance, a rhymed pair of lines of iambic pentameter make a 'heroic couplet' or aa, bb, cc, rhyme pattern. Likewise, the lines of unrhymed iambic pentameter are commonly known as 'blank verse.' So there are three types of verses in terms of rhyming scheme i.e. metrical verse, blank verse, and free verse.

Metrical foot: The knowledge how the metrical foot is constituted in the process of versification is very important while dealing with the poetic analysis. Metrical foot has a key role in the metrical poems which is constituted with the combination of two syllables (disyllabic foot i.e. iambic, trochaic foot) or the combination of three syllables (tri-syllabic foot i.e. anapestic, dactylic foot). The type of foot determines the kind of meter used in verse.

Alliteration: Alliteration is the repetition of similar consonant sound in the initial position of two or more than two words in the same verse line. Wales regards it:

as a deliberate phonological device, it is associated mostly with literary, especially poetic, language; but it is also found in popular idioms (e.g. rack and ruin; as dead as a doornail), tongue twisters (Peter piper picked a peck of pickled peppered, etc.), advertising language (Guinness is good for you). (14)

Assonance: It is "sometimes called 'vocalic rhyme' which consists of the repetition of the similar vowel sounds usually close together, to achieve a particular effect of euphony" (Cuddon 58). The similar vowel sound occurring in the neighboring words is often termed as assonance. In this regard, Wales holds the view as "assonance is a partial or half rhyme much used in poetic language as an aspect of sound patterning and cohesion. She further says, "The same (stressed) syllable is repeated with words but with different final consonant (e.g. cough drop; fish chips)" (33).

From the following couplet by Alexander Pope, we can explore some of phonematic units as have been discussed above. Let us consider the couplet as:

W̌e thīnk ǒur fătȟers fōol ăs $\bar{w}$ ise w̌e grow Ǒur wišer sōns, ňo dōubt, w̌ill think ǔs so;

The above couplet consists of five unstressed ( ${ }^{\searrow}$ ) syllables and five stressed $\left(^{-}\right)$syllables. This means, each verse line consists of ten syllables. The combination of two syllables $\left[^{-}{ }^{-}\right.$] i.e. unstressed and stressed respectively, constitutes one iambic foot. In this way, the ten syllabic verse lines has five (iambic) feet which is technically known as 'iambic pentameter line'. 'Iambus' is one of the most common English meters. .Meter in the poetic text is determined by the type of foot and the number of foot/feet involved in a line. Thus, a line with three iambic feet is known as iambic trimeter. A line with six dactylic feet is known as dactylic hexameter. 
Let us consider some common English meters as follows:

\begin{tabular}{|c|c|c|c|c|}
\hline S.N. & Foot Type & Style & Syllable Pattern & $\begin{array}{l}\text { syllable } \\
\text { count }\end{array}$ \\
\hline 1. & Iambus & Iambic & Unstressed + Stressed $\left({ }^{-}\right)$ & Two \\
\hline 2. & Trochee & Trochaic & Stressed + Unstressed $\left({ }^{-\smile}\right)$ & Two \\
\hline 3. & Spondee & Spondaic & Stressed + Stressed $\left(^{--}\right)$ & Two \\
\hline 4. & Pyrrhic & Pyrrhic & Unstressed + Unstressed ( ${ }^{-}$) & Two \\
\hline 5. & Anapest & Anapestic & 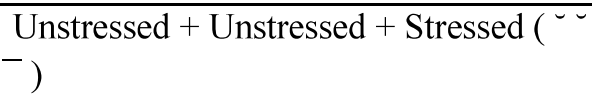 & Three \\
\hline 6. & Dactyl & Dactylic & $\begin{array}{l}\text { Stressed + Unstressed + Unstressed ( } \\
\checkmark)\end{array}$ & Three \\
\hline 7. & Amphibrach & Amphibrachic & $\begin{array}{l}\text { Unstressed }+ \text { Stressed }+ \text { Unstressed }\left({ }^{-}\right. \\
-)\end{array}$ & Three \\
\hline
\end{tabular}

The stressed mark $\left(^{-}\right)$is termed as macron and unstressed mark ( $\left.{ }^{-}\right)$is breve.

Following are the types of meter and the line length:
1. Monometer
One foot
2. Diameter
Two feet
3. Trimeter
Three feet
4. Tetrameter
Four feet

5. Pentameter

Five feet

6. Hexameter

Six feet

\section{Heptameter}

Seven Feet

8. Octameter

Eight feet

In the above discussion, linguistic patterns like meter, rhythm, syllable and metrical foot/feet have been briefly mentioned, now the discussion turns to the other phonological features as rhyme, alliteration and other aspects. In the same couplet:

W̌e thīnk ǒur fătȟers fōol ăs wise w̌e grow

Our wišer sōns, ňo dōubt, w̌ill think ǔs s̄o;

the ending word 'grow' /grəo/of the first line and 'so' /səo/ of the second line ending have the similar sound /əo/. This sameness as Sinha views, "the repetition of similar sounds in the similar positions" (37), is known as the rhyme. Similarly, the sounds /w/ and /f/ are repetitive sounds in the first line; and the sounds $/ \mathrm{w} /$ and $/ \mathrm{s} /$ are alliterative sounds in the second line. The rhyme and alliteration are used to make the poetry sound more musical as well as melodious.

They provide the ears an audible pleasure. They have, besides, a great rhetorical effect for the repetition of the same letter or sound of the prominent words in the lines which, no 
doubt, serve to make more emphatic. They have, furthermore, permanent effect in the listeners. This might be obvious reason of why the ancient verses are surviving to the date.

So far as the linguistic sound related pattern 'assonance' is concerned, it is also found in the above poem. The intervocalic sound as /I/ in the second line 'will' and 'think' consist of the assonance. In the strict sense, the similar vowel sound that occurs in the middle position of two or more than two words (i.e. snail's daily ways /eI/) is called assonance but in a looser sense as Wales views, assonance is sometimes more loosely used to refer to all kinds of phonological recurrence or juxtaposition" (33).

\section{Phonology and Analysis through Manner and Place of Articulation:}

Vowel phonemes (sounds): Vowel sounds are described in terms of which part of the tongue becomes active and how high the tongue rises while a particular vowel sound is articulated. From the position of the tongue, the vowel sounds are categorized in three types: high vowels (i, I, u, $)$ ), mid vowels $(e, \varepsilon, \Lambda, \partial, \supset, p)$ and low vowels $(æ, a)$. Similarly, from the part of the tongue that becomes active in articulating vowels can be classified into three kinds: front vowels (i, I, e, $\varepsilon, æ$ ), central vowels ( $\Lambda, \partial, a)$, and back/dark vowels (u, $v, \mathfrak{p}, \supset$,$) .$

Generally, question may arise as what the position and activation of the part of the tongue have to do with the analysis of the poetic text. In first view, it seems to be absurd talking about literary texts that are analyzed considering the vowel sounds' articulatory manner and position. But the modern analytical or interpretative convention considers the articulative aspects very important in the interpretation of pattern and meaning of the poetic texts. For instance, dark vowels $(u, v, p, o)$ are used in the higher frequency to express the sad and unpleasant thoughts. The front and high vowels ( $\mathrm{i}, \mathrm{I})$ are mostly used in the liturgical language that is, the addressed ones are highly venerable. Similarly the ideas suggesting of low status are expressed employing the low vowel like /æ/ and /a/. Lastly but not least the central vowel especially the mid - central vowels $/ \Lambda$ and $/ \mathrm{a} /$ may be employed to denote the central thing of creatures that is 'love' $/ \Lambda \mathrm{v} /$. The sense of 'love' as Freud views it as 'libidinal (life) instinct' to which he means 'the desire for living.'

To mention about the features of the diphthong, Simpson views that there "is nexus of phonetic contrasts between front and back vowels (eh/oo), between open and close vowels (uh/eea), between lip rounded and unrounded vowels (oo/eh), and between shorter and longer vowels (oh/uh)"(68). He states that such constant movement of high and low, back and forth, and up and down has much to do with association sense of text. He relates the fluctuation to the bird's fly of the poem 'The Windhover' by Gerard Manley Hopkins (1844-1889).

The English consonant sounds ( 24 phonemes) are classified into two major groups that is, the pleasing sound (sonorant sounds) and unpleasing (harsh) sounds. Along with the all vowels, 
the nasal consonants $(m, n, y)$, liquids $(j, r)$, and glides $(w, y)$ are considered to be sonorant sounds. In contrast, plosive sounds (p, b, t, d, k, g), fricatives (f, v, $\theta$, , , s, z, z, $\int, 3, \mathrm{~h}$,), and affricates $\left(t^{s}, d z\right)$, are considered to be the harsh (cacophony) sounds.

(http://www.literarydevices.com/cacophony/)

Euphony is the combining of words that sound pleasant together or are easy to pronounce, usually because they contain lots of consonants with soft or muffled sounds (like $1, \mathrm{~m}, \mathrm{n}$, and r) instead of consonants with harsh, percussive sounds (like t, p, and k). Other factors, like rhyme and rhythm, can also be used to create euphony. An example of euphony is the end of Shakespeare's famous "Sonnet 18," which goes "So long as men can breathe, or eyes can see, / So long lives this, and this gives life to thee." (https://www.litcharts.com/literary-devicesand-terms/euphony)

Cacophony is the use of a combination of words with loud, harsh sounds - in reality as well as literature. In literary studies, this combination of words with rough or unharmonious sounds is used for a noisy or jarring poetic effect. Cacophony is also considered the opposite of euphony which is the use of beautiful, melodious-sounding words. It is used to create harshsounding sentences and tones which often mirror their subject matter: noisy, energetic, chaotic, or unwanted characters and things. It makes use of connotative sounds to create disgust, frustration, or interest in the reader with loudness, noisiness, and energy in hard consonant sounds. Cacophony creates interesting poems, emotive prose, and playful songs.

(http://www.literarydevices.com/cacophony/)

Example: "Full Fathom five thy father lies $\cdots$

Hark! Now I hear them - Ding don Hark! Now I hear them - Ding-dong bell." William Shakespeare, Tempest, Act I, Sc. II

In the above octave stanza, only the first and last (eighth) lines have been presented here to show the example of cacophonous sounds occurred in the high frequency so as to relate sense of frustrating view about the death. The first line "Full Fathom five thy father lies" includes fricative sounds $\mathrm{f}, \mathrm{v}, \theta, \partial, \mathrm{s}, \mathrm{z}$, which are dominant in this line and the last line "Hark ! Now I hear them - Ding dong bell" majority the stressed sounds are fricative $/ \mathrm{h} /$ and plosive sounds $/ \mathrm{k}, \mathrm{b}$ and $\mathrm{d} /$ which are harsh sounds (cacophony).

\section{Phonematic Unit and Variation in Verse}

Syllabic structure and rhyme pattern are the determinant aspects in the variation of the verse. "Verses (Latin - versus 'turning) as stated by Bose and Sterling, are the lines of poetry combined into regularly accented groups of syllables which are called measure" (132). The 
poetic lines are called verses because when the meter of the line is completed the writer turns to place another under it. The verse has three variations:

Metrical verse: If a poem has the both regular rhythm of fixed number syllables in each line and specific rhyme scheme, it is called metrical verse. In other words, metrical verse must meet the two requirements that is, the regular rhythm and rhyme pattern.

Blank verse: blank verse is the poetry written in regular metrical form but unrhymed line almost always in iambic pentameter line i.e. 'ten syllables in the sequence of unstressed stressed $\left({ }^{-}\right)$.

You stars that reign'd at my nativity,

Whose influence hath allotted death and hell

Now draw up Faustus like a foggy mist

Into the entrails of yon labouring clouds. Christopher Marlow's Play 'Dr. Faustus' In the above verse lines, each line consists ten syllables or five disyllabic feet in unstressed stressed sequence, thus iambic pentameter. Only what it lacks is the rhyming pattern.

Free verse: As its name suggests that this kind of poem does not follow the consistent metrical pattern, rhyme scheme and there is variable lines' length. This is sometimes called as prosaic poem free from the prosodic canon.

Example: Landlord, landlord,

My roof has sprung a leak

Don't you 'member I told you about it

Way last week? Landlord, landlord. Langston Hughes, "Ballad of the Landlord"

These above lines are unequal, unrhymed, and irregular rhythm.

\section{Summary and Conclusions}

\section{Summary}

The English language has forty four segmental sounds in which twenty four sounds are consonants and twenty are vowel sounds. Within twenty vowel sounds twelve are monophthongs and rest eight are diphthongs. These linguistic sounds can play a crucial role in the poetic analysis. The poetic texts can be analyzed and interpreted in terms of various sound patterns used in the poetic discourse. Through the sonic pattern, the syllable number and types, rhythmic features, rhyme scheme, alliteration, assonance, metrical foot, and even metrical type

are analyzed. The next aspect of the phonic role is that the kind of emotion, attitude and tone of the expression are explored through use of sound pattern in the texts. The sounds are of different features and characteristics. In this way, from the repetitive pattern of specific sounds, 
we can explore the intension of the author. Similarly, the linguistic sounds can help to make distinction what kinds of verses are in the particular text.

\section{Conclusions}

Phonology or linguistic sound pattern can play an inevitable role in the composition of poetic discourse and thus in the interpretation and analysis of the text. Also the sound pattern is essentially important to determine and to distinguish various poetic elements and features. Basically there are main two types of sound sequences. The first is that syllabic structure, rhythmic pattern, metrical foot/feet, alliteration, assonance, and intra-line rhyme are analyzed through horizontal (linear) sequence or technically called as 'syntagmatic' relation and the next rhyme scheme and stanza form are analyzed from the vertical sequence or technically termed as paradigmatic relation. The frequency of occurrence of particular sounds connotes variously depending on the type of characteristic features certain sounds are supposed to have. In the same way, the variations in the verses also suggest the different emotional as well as expressive range of the poets. The kind of idea or feeling expressed through the blank verse may not be exactly exposed though the metrical verse. Same is the case with the free verse in comparison to others. To sum up, apart from the basic primary function of linguistic sounds in language structure, phonology can be a reliable means for the interpretation and analysis of poetry beyond and above the basic primary function of sound pattern.

\section{Work Cited}

Bloch, Bernard. "A Set of Postulates for Phonemic Analysis." Language 24, 1948.

Bose, Rai Radhika Nath and T. S. Sterling. Elements of English Rhetoric and Prosody. Chuckerverty, Chatterjee and Co, 1997.

Byram, Michael, editor. Routledge Encyclopedia of Language Teaching and Learning. Routledge, 2011.

Crystal, David. A Dictionary of Linguistics and Phonetics. $6^{\text {th }}$ ed. Blackwell, 2008.

Cuddon, J. A. A Dictionary of Literary Terms and Literary Theory. $4^{\text {th }}$ ed. Mayablackwell, 1998.

Firth, John Rupert. "A Synopsis of Linguistic Theory." Studies in Linguistic Analysis. Philological Society), 1957 (1930), pp.1-32.

Goldsmith, John. Autosegmental and Metrical Phonology. Basil Blackwell, 1990.

Hockett, Charles. A Manual of Phonology. Indiana University Publications in Anthropology and Linguistics 11. 1955. 
122 JODEM: Journal of Language and Literature, vol. 10, no. 1, issue 12, 2019/2076BS

Jakobson Roman. "Closing Statement: Linguistics and Poetics," in Style in Language (editor: Thomas Sebeok), 1960.

Ladefoged, Peter. A Course in Phonetics. $4^{\text {th }}$ ed. University of California, 2001.

Lazar, Gillian. Literature and Language Teaching: A Guide for Teachers and Trainers. Cambridge UP, 1993.

Langston, Hughes. "Ballad of the Landlord." Joys of Reading: A Collection of Essays, Short Stories, Poems and Plays, Compiled by Shreedhar P. Lohani and Rameshwar Adhikari. M. K. Publishers, 1999.

Marlowe, Christopher. Doctor Faustus. G. R. Kanwal. Compiler. Surjeet Publications, 1978.

Pope, Alexander. "An Essay on Criticism." English Critical Texts, edited by D. J. Enright, and Ernst de Chickera. Oxford UP, 1991.

Richard Ogden, An Introduction to English Phonetics. Edinburgh UP, 2009.

Simpson, Paul. Stylistics: A Resource Book for Students. Routledge, 2011.

Richards, Jack C., John Platt, and Heidi Platt. Longman Dictionary of Language Teaching and Linguistics. Longman, 1999.

Sinha, A. K. A Students' Companion to English Poetry. Bharati Bhawan, 1992.

Thornborrow, Jaonna, and Shan Wareing. Pattern in Language. Routledge, 2010.

Traugott, Elizabeth Closs, and Mary Louise Pratt. Linguistics for the Students of Literature. Oxford UP, 1980.

Wales, Katie. A Dictionary of Stylistics. $2^{\text {nd }}$ ed. Longman, 2001.

(http://www.literarydevices.com/cacophony/)

(https://www.litcharts.com/literary-devices-and-terms/euphony) 